\title{
THE FEATURES OF INDIAN DIASPORA AND THEIR IDENTITY IN JUMPHA LAHIRI'S SHORT STORY "UNACCUSTOMED EARTH”
}

\author{
Tri Sugiarto \\ Universitas Negeri Yogyakarta \\ email: trisugiarto@uny.ac.id
}

\begin{abstract}
(Title: The Features of Indian Diaspora and Their Identity in Jumpha Lahiri's Short Story "Unaccustomed Earth"). America is a multicultural country. It results from the immigration of various ethnic backgrounds from Asia, Africa, and Europe since the beginning of the 19th century. As one of the ethnic communities in the US, the Indian diaspora encounters many experiences in their life. This article explores the feature and identity of Indian diaspora represented in Lahiri's "Unaccustomed Earth". It aims to reveal some of the Indian diaspora's features in the US and concludes their current cultural identity through analytical reading of the short story. This is a qualitative content analysis. It applies a theory of diaspora to dig the underlying information from the data. The study shows that Indian diaspora experience several features that include having trouble at their first interaction in the country, recalling the tradition of the homeland, associating with the people from the same ethnic background, and processing the idea of going home to the homeland. In the short story, it is found that the characters embody a hybrid identity.
\end{abstract}

Keywords: Indian, diaspora, identity, hybrid, America

\section{INTRODUCTION}

The immigration to the United States has started since the first settlement of the European people in the 1600s. This was continued with another movement of the people from Asia and Africa at the beginning of the $19^{\text {th }}$ century because of military invasion, colonization, or financial hardship in their home country (Ashcroft et al., 2006). These people struggle to find an opportunity to live a better life in the new "home" while also carrying and practicing their root culture and tradition. The number of immigrants from these different sites of the world has formed the United States as a multicultural country. The concept of Salad Bowl then is closely associated with America, a place where people from different ethnic backgrounds and experience life as a diaspora society.

Indian is one of the diaspora societies living in America. The immigration of the people to the country has started since 1980 (Bagoria, 2020) The phases of their arrival were usually divided into four different phases. The first one was at the beginning of the $19^{\text {th }}$ century with a small number of people. This was when India was still under the colonization of Great Britain. The second phase was in 1947, after the country's independence. Together with Pakistani, Indians traveled to America in a bigger number than to the first phase. The enactment of Immigration law 1965 signed as the third phase of immigration of the people from India. In this phase, US 
immigration policy has allowed immigrants to bring their spouses and children to the country and granted the citizenship that allowed them to vote. Consequently, it has motivated more Indians to move to America. The needs of skilled labor on technology attracted more immigrants from India to flee to America in 1990. Indians in the US became one of the largest tribes among other ethnics who stayed there. They work in various professions such as labor at the industrial company, teacher, lecturer, professor, and writer.

Among some diaspora writers who reside in the US, Jhumpa Lahiri is one of the writers who has produced some literary works that have gained popularity in the US and also other countries. Her writings mainly concern about multicultural issues of immigrants from India to coping with the lives in the United State or dilemma with their homeland's tradition and culture. She is the second generation of Indian descendant was born in London and moved to the US at the age of three. Her parents are an Indian descendant of Bengali Indian. Lahiri starts her debut in writing with publishing a collection of short stories entitled Interpreter of Maladies (1999). This work gained Pulitzer Prize for fiction in 2000. She wrote another novel The Namesake in 2003, which is adapted into a movie with the same title, and the second collection of short stories Unaccustomed Earth that has won the 2008 Frank O'Connor International Short Story Award and became the number one on the New York Times Book Review list of "10 Best Books of 2008.

Many critics believed that the second collection of Lahiri's short stories exhibits her literary genius. The complexity of the issue in her stories is the cause of the claim. In the publication of the collection of short stories Unaccustomed Earth (2008), the first story, which has the same title as the book "Unaccustomed Earth". It focuses on portraying the life and relationship of the first and second generation of an immigrant from India. It narrates about a father who visits her daughter in her new house in Seattle. He has traveled to many places in Europe after the death of his wife. He is now confused by his thought on whether he will stay with his daughter or keep staying alone in his condominium for his old days. In the Indian tradition, it is normal that a daughter takes care of her single-parent. Ruma, his daughter also suffers from the same dilemma. She understands the traditional convention but she also needs to consider the perspective of her father and also her husband. She marries an American man, who is working out of town during her father's visit. Ruma used to have bad communication with his parents, and this makes the interaction feels awkward and more confused to determine whether she will ask him to stay or not. After staying together with her father and finds out that he connects with his grandson very well, Ruma is assured to ask him to move with her family. Nevertheless, he refuses and she finds a secret that may cause him to prefer staying in his own house.

This article explores the characteristics and cultural identity of Indian diasporic society in America reflected from Lahiri's first story "Unaccustomed Earth". The reading of the story applies post-colonial theory. This theory is chosen because it provides a methodology to think through the similarities and differences of attitudes, culture, and language of the colonized people that are reflected before and after the coming of colonizers (Ashcroft et al., 2007). The postcolonial theory also involves a discussion about various features. One of the features occasionally discussed is the diaspora. 


\section{METHODS}

It is a descriptive-qualitative research analysis that applies the content analysis method to identify the features of Indian diaspora and their cultural identity in Jumpha Lahiri's short story "Unaccustomed Earth". The source of the data is part one from Lahiri's collection of short stories Unaccustomed Earth. the data of the research are in the form of words, phrases, and sentences from the short story. They are read and reread repeatedly to gain some data supporting the focus of the investigation. The collected data relevant to the research are grouped and analyzed using the theory of diaspora.

\section{RESULT AND DISCUSSION Result}

Based on Cohen's (Cohen, 1997) identification of types of diaspora, Indian diaspora belong to the cultural diaspora. This category refers to the fact that the process of migration of Indians to America does not only include the movement of their physical body but also the migration of ideas, tradition, language, and music from the home country. Applying diaspora theory, the investigation finds some interesting Indian diasporic features reflected in Lahiri's short story "Unaccustomed Earth". Either first or second generation of Indian diaspora in America may experience some challenges that include problems with the host culture, keep the tradition from the home country, socialize with people from the same cultural background, and enthusiast to visit home country. Furthermore, based on the elaborated data, it is concluded that the identity of the Indian diaspora in the short story has shifted from their common image of Asian into something new, which also distinct from the host identity. They could not express themselves as a total
Indian or American. They are Indian-American who are characterized as having a hybrid cultural perspective and identity.

\section{Discussion}

The Experience of Indian's Diaspora in America reflected

\section{Having a Troubled Interaction}

It is always difficult for the first generation of immigrants to adapt to the situation in a new country. The language and also culture in the host country are usually different and often contradictory to the home of the immigrants. The experience of Indian diaspora in America is one of the examples. Even though India was colonized by Great Britain, and English is the language of colonization, it is not easy for them to exercise the language in the context of the United State. Some dictions have changed from the meaning in British English, and also they are pronounced differently.

Despite some possible reasons justifying why Indian immigrant in America could hardly communicate with some locals in their first contact, which includes their education background, economy, intellectuality, and many others, Lahiri's "Unaccustomed Earth" exemplifies a situation where the first generation of Indian diaspora settle in America and experience a problem because of the language barrier.

"There he was reminded of his early days in America, understanding only a word or two of what people said, handling different coins" (28).

Ruma's father is stumbled upon his memory of living in America in his early time. Although he is now familiar with the life, the language, and America's social situation, particularly in Pennsylvania, Seattle, Brooklyn, he acknowledges that it was difficult to communicate in the country at the beginning. 
Thus, from the situation experienced by Rumas' father, adjusting life in a foreign country for the first time requires a good mastery of the language spoken by its 'natives'. Many immigrants are usually less proficient when they travel and settle abroad. Indian diaspora who were expanded from their first settlement in Europe to America were usually manual labor with a less academic qualification. The US enacted a policy to facilitate the language proficiency of immigrants so that they could interact better with their surroundings. Usually, the spirit to make living, to build a good life, and to change social status motivates them to master the language spoken by the US citizen.

\section{Recalling to the Tradition of Homeland}

Diaspora society always maintains the language, culture, and tradition of their home in their new place. This practice makes them feels at home and confirms their effort to preserve their cultural identity. They also keep the collective memory and myth about their homeland and usually narrate them as the bedtime story to their son or daughter. Therefore, their next generation will not lose the connection to the parent's land and ancestor.

In Lahiri's "Unaccustomed Earth", the practice of tradition in the host country is different between the first and second generation of immigrants. Ruma's parents, as the first immigrant, continue to preserve the tradition and culture that Bengali people used to do in their home country, while Ruma mostly does not do the same thing.

"But he continued removing his sneakers, setting them in the foyer next to the main table before straightening and acknowledging his surroundings (13)
In India, removing shoes or sandals when entering a house is a common norm and widely shared by the people of the country. It is a part of their custom and as one of the ways to respect the owner of the house. This behavior also keeps the house clean from dirt and protect the people living in the house from a threat of illness from an entrance of unclean shoes. Ruma's father preserves this custom and practice it during his visit to Ruma's house. Unfortunately, this is something that Ruma never does and teaches her son. Therefore, her son is curious about his grandfather's attitude. He never sees this act in his house and then wants to do the same thing as his grandfather.

"I want shoes off, too." Akash stopped his sandals on the floor (14)

Another cultural practice that Rumas' father maintains and applies during his visit is the tradition of eating with fingers. While it is also the customary eating method in India, Ruma also never does this or introduce the practice to her son. So, he is also interested to try eating with fingers like his mother and grandfather.

"She ate with her fingers, as her father did, for the first time in months, for the first time in this new house in Seattle. Akash sat between them in his booster seat, wanting to eat with his fingers, too...." (22)

As the second generation of an Indian immigrant in America, Ruma has not practiced many Indian traditions in her family. However, among the many traditions of India that she does not continues, she keeps using some Bengali words in her communication. She and 
her father use Bengali's addressee terms, such as Baba instead of "father", Dida as to replace the word "mother", $B a b u$ as to call "dear son" and Dadu as to name grandfather. Ruma introduces some Bengali to her son and he uses one of the words to call his grandfather. Ruma's father also teaches Akash Bengali language when he was playing with him.

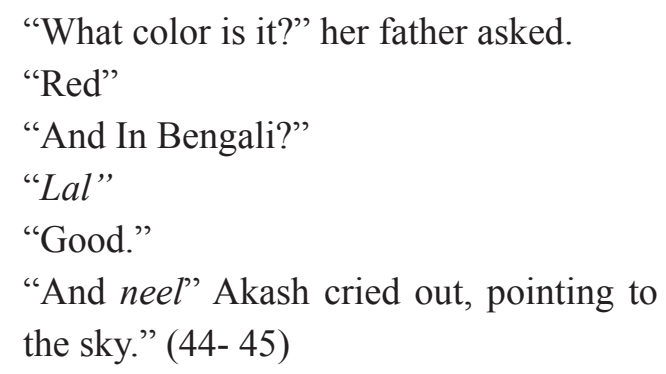

Ruma's father trains Akash with Bengali while they work together in a garden. $\mathrm{He}$ wants to make sure that the language continues to be spoken by his next generation living in America. He is sad to find that many of the customs that he and his wife sustain when raising Ruma and her brother has been discontinued. Akash is strange with his ancestor tradition because some traditions that represent the home country are gone or stopped to be introduced to him, as the youngest generation.

Besides, it is the caring for family inspired by her mother's tradition, rooted from traditional patriarchal tradition in India, that Ruma decides to continue. She prefers to dedicate herself to take care of her family, like her mother. She used to work and build good interaction and communication with many people. After she marries Adam, she continues her activity to work, besides taking care of the family. However, the loss of her mother has saddened her. She decided to quit her job. She decides to dedicate more to her family, as her mother and many women do in India.
Ruma symbolizes an obedient and good woman living in a patriarchal society. It is indicated when she assures her father that raising her children is a work that will make her busy all day. Thus, it is not necessary for women to find work outside.

"I am working, Baba. Soon I'll be taking care of two children, just like Ma did." "Will this make you happy?" She didn't answer him. Her mother would have understood her decision, would have been supportive and proud. (36)

Ruma's father is more feminist than herself. He agrees that women may work outside of the house because it maintains mental stability, saves her from being bored, and releases from domestic responsibilities, and also helps to add the family's income. $\mathrm{He}$ wonders why Ruma does not work and asks her to get a job. Ruma believes that she is working to raise her children, and this is a good job she takes. She adds that this work shall be the best work the women should do and argues that her mother must be very proud of hearing her decision to do so.

\section{Associating with the Same Ethnic Community}

It is depicted in Lahiri's "Unaccustomed Earth" that Ruma misses Pennsylvania and New Jersey, the place she and her brother grew up. She has beautiful memories there. Besides, the city has many Indian diaspora who share the same cultural background as her.

"... she lived on a separate coast thousands
of miles from where she grew up, a place
where her parents knew no one, where
neither of her parents, until today, had set
foot. The connections her family had 
formed to America, her parents' circle of Bengali friends in Pennsylvania and New Jersey, her father's company, the schools Ruma and Romi had gone through, did not exist here" (11)

From the quotation, it is expressed that the bond among Indian diaspora in America is strong. Ruma remembers the beauty of comradeship that her parents have formed with other Indian diaspora when they lived in Pennsylvania and New Jersey. She realizes that she lives far from the place surrounded by people with the same cultural background now. She recalled the romance of togetherness with people sharing the same customs.

Being different in a foreign land makes the unity of the immigrants usually grow stronger. By grouping and interacting with the one whose tradition and the root is familiar with them, unfamiliar circumstances will change into comfort and a safe place. Ruma's father is often gathering with people of the same ethnic background, spending time together, and enjoying the traditional Indian menu. They form their way to build a good relationship and maintain their cultural identity.

"In the old house, he was still stuck in his former life, attending by himself the parties he and his wife had gone to, getting phone calls in the evenings from concerned friends who routinely dropped off pots of chicken curry or, assuming he was lonely, visited without warning on Sunday afternoons" (11)

From the quotation, it is reflected that caring and giving sympathy to Ruma's father keeps coming from friends with the same ethnic background after the death of her mother. They keep visiting and bring him some Indian food to the house to make her father happy and not being trapped by loneliness.

Furthermore, it also appears in "Unaccustomed Earth" that Ruma's father is comfortable sitting near Mrs. Bagchi, an Indian woman who takes the same trip with him in Italy. She has moved from India to America since young because she avoids the arranged marriage with someone he does not love. She has adapted the behavior and way of thinking of the Americans. She an independent, open-minded, and successful woman. The same appearance and language that she shares with Ruma's father have made him believe that she is a good friend to talk within the journey. Among other traveler's buddies in the tour group, he has fallen in love with Mrs. Bagchi because she shares a physical and cultural background he is familiar with.

In short, some immigrants living in America prefer to stay within the community who shares the same ethnic background. They earn money for the family, maintain their cultural and traditional belief, experience stability and satisfaction as they live together with their community. Because some immigrants usually find difficulties in adapting themselves with the host country culture, they tend to look for the same ethnic community to settle with, so they can share and maintain their cultural identity. Besides, diasporic communities often perceive their presence is not well accepted by some people from host country. Therefore, the only choice to strengthen their presence and existence is by maintaining a good relationship with the same ethnic community.

\section{Possessing the Idea of Returning Home}

Diaspora society's strong link to their 
homeland drives them to schedule on a trip for going home to their home country. This is even stronger when the immigrants still have parents, relatives, siblings in the homeland. The visit to the country is a must and will be best prepared. This situation is represented in Ruma's father and some of his friends in America who believe that that visiting India is a must-do journey.

"Those returns to India had been a fact of life for him, and all their Indian friends in America" (8)

This is also supported by his wife who believes that going back to India, to visit parents and relative is important and very meaningful

"He had found his wife's interest surprising; throughout most of their marriage, it had been an unquestioned fact that visiting family in Calcutta was the only thing worth boarding a plane for.

People living outside of their native land concern so much to his origin (Herrero \& Huntington, 2004)2004. 448p. \$27.00. Samuel Huntington suggests in this book that American national identity is threatened by a tidal wave of Latino-primarily Mexican-immigrants who are refusing to assimilate to American \&ldquo;Anglo-Protestant\&rdquo; values, and who are facilitated in this resistance by the erosion of elite support for those very same values. That erosion is a consequence of the \&ldquo;cults of multiculturalism and diversity\&rdquo; (p. 144. Their association with the country cannot be dismissed and faded. Ruma's father feels the same way as the other Indians living in America. The binding of their life to India will never stop, and it will always become their life chronicle. Moreover, Ruma's mother believes that visiting India is worthy and the best destination to wander. The family believes that it is always a tremendous and fun journey to visit their home country.

\section{Indian Diaspora Cultural Identity in the United States}

Indian diaspora living in the US has grown into a big number. It was already reached 2.4 million Indian diaspora in the US in 2015 (Zong \& Batalova, 2017). They are mostly concentrated in metropolitan areas such as New York as well as Washington D.C., Boston, Philadelphia, Atlanta, Chicago, Dallas, Houston, Los Angeles, and San Francisco. Living in a big metropolitan city makes interaction with people from a different culture is impossible to avoid. Therefore, maintaining cultural identity rooted in the homeland in the host country is not going to work. It has to adapt to the local culture as well as a culture brought by migrants from other countries.

In Lahiri's "Unaccustomed Earth" the identity of the characters is a hybrid cultural identity. It builds upon two different traditions that combine and stand as something new either from the host or homeland cultural tradition. Ashcroft (2006) defines it as something which is not constructed from the disappearance of independent cultural traditions, from which it firstly springs, but a continual and mutual development of the existing features. In Ruma's father and her case, they maintain Bengali culture and tradition brought from India to the United States, but they assimilate with the existing culture in the culture of their neighborhood. Thus, the original tradition is no longer very vivid, and so does the American tradition the 
adopt is not very strongly influence their mindset.

It is learned that Ruma does not teach Akash any culture of Bengali. She cannot even cook the traditional cuisine of India and speaks Bengali very rarely, only when her family sends her greeting card and gift for Akash on his birthday. Yet, this absence does not strongly imply that Ruma has embodied white American tradition. She is a mixture of the two cultures situated in her home as an Indian immigrant daughter and a wife of a white man with a strong American or white civilization.

"By now Akash had forgotten the little Bengali Ruma had taught him when he was little. After he started speaking in full sentences English had taken over, and she lacked the discipline to stick to Bengali. Besides, it was one thing to coo at him in Bengali, to point to this or that and tell him the corresponding words. But it was another to be authoritative; Bengali had never been a language in which she felt like an adult. Her own Bengali was slipping from her. Her mother had been strict, so much so that Ruma had never spoken to her in English. But her father didn't mind. On the rare occasions Ruma used Bengali anymore when an aunt or uncle called from Calcutta to wish her a Happy Bijoya or Akasha Happy Birthday, she tripped over words, mangled tenses. And yet it was the language she had spoken exclusively in the first years of her life" (12)

This quotation reflects that Ruma grows in a setting that allows her to learn both English and Bengali, and also their tradition and culture. Although it is seldom for her to speak Bengali, she cannot separate from the fact that she was raised with it. The blood of Bengali flows in her vein. She is an American but she is not "an American" because she speaks English and lives there for many years. She possesses a distinct physical and emotional embodiment dissimilar to the white American that is usually represented as independent, wealthy, obnoxious, loud, and often ignorant, drunk, sloppy. She is a mix of both the Bengali and American culture.

Furthermore, the same identity also applies to Akash. Undeniably, physically he is a mix of Bengali and American. He stays and accustomed to the American way of life. Yet, given the lesson about Bengali by his grandfather will affect his perspective to Bengali's custom and tradition. He also possesses a hybrid identity, both physically and emotionally.

Ruma's father and Mrs. Bagchi correspond to hybrid identity too. As the first generation of an immigrant in America, they bring with them many traditions, culture, and perspective of Indian to America. However, they assimilate and adapt to the host culture and tradition. Thus, they can be accepted and stay comfortably in his neighborhood.

"He was wearing a baseball cap that said POMPEII, brown cotton pants and a skyblue polo shirt, and a pair of white leather sneakers. She was struck by the degree to which her father resembled an American in his old age" (11)

The quotation above explains that Ruma's father assimilates to the existing trend of fashion of American people. He has doubling himself as Indian-American with a conscious or unconscious new ideology and attitude. Bagchi also experiences the same thing as Ruma's father. She is still an Indian woman, physically, 
but adjusts to the uniqueness of tradition and culture she faces in America. She becomes independent and prefers to put on the western outfit rather than Indian traditional cloth (15).

\section{CONCLUSION}

Lahiri's "Unaccustomed Earth" provides a story about Indian immigrant's experience and dynamic of living in the United States. They bring their native language and their local traditions when they reached the land of America. They assimilate and adapt to the culture and situation in the new place to survive. Many things are not easy for them in the beginning. They find it hard to communicate in the first contact. The romance of home haunts and cannot also be dismissed from their life as an IndianAmerican.

From the short story, it is found that the first generation of Indian diaspora in America maintains and practices several features of Indian culture in the host country while also keeps himself adopting the dynamic of the US white culture. Ruma's father keeps behaving traditionally during his visit, for instance by eating with fingers, removing shoes before entering the house, and speak Bengali to his grandson. He teaches the language to his son to keep him rooted in his cultural background. $\mathrm{He}$ introduces many things new for his grandson.

Although the second generation of Indian immigrants in the US does not consistently maintain several traditions that are mostly practiced by the first generation, Ruma keeps several traditions that the culture taught her when she was young. She, for instance, using some words originally from Bengali in her daily interaction with his father and son. She also follows the belief of many women in India, including her mother, about the role of a woman in a family. She chooses to be home and takes care of family than go back to work.
The changing mindset, way of dressing, and use of language which is mostly English do not imply that the first or second generation of Indians living in America turns their identity into the white supremacy culture. As their physical look does not change, their perspective and ideology still keep the personality of the East, India. They experience transformation from both the home and the host culture into something distinct. It combines the identity of east and west into one new identity.

\section{REFERENCES}

Ashcroft, B., Griffiths, G., \& Tiffin, H. (2006). The Post-Colonial Studies Reader. In B. Ashcroft, G. Griffiths, \& H. Tiffin (Eds.), The PostColonial Studies Reader. Routledge Taylor \& Francis Group. https://doi.org/10.2307/3201254

Ashcroft, B., Griffiths, G., \& Tiffin, H. (2007). Post-colonial Studies Key Concepts (2nd Editio). Routledge Taylor \& Francis Group.

Bagoria, M. (2020). Tracing the Historical Migration of Indians to the United States. Proceedings of the Indian History Congress, 70(May), 894-904. https:// www.jstor.org/stable/44147737

Cohen, R. (1997). Global diasporas; An Introduction. University of Washington Press.

Herrero, F. G., \& Huntington, S. P. (2004). Who Are We? The Challenges to America's National Identity. Revista de Crítica Literaria Latinoamericana. https://doi.org/10.2307/4531363

Zong, J., \& Batalova, J. (2017). Indian immigrants in the united states. In Migrationpolicy.Org (pp. 1-12). https:// www.migrationpolicy.org/article/indianimmigrants-united-states 